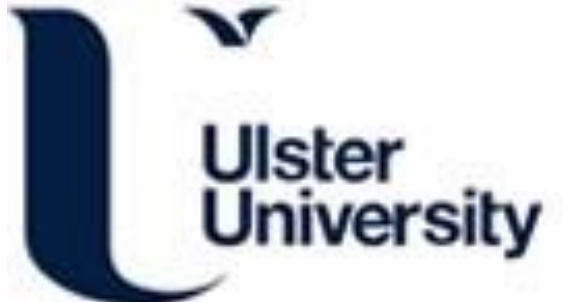

\section{Numerical simulation of Bridgman solidification of binary alloys}

Battaglioli, S., McFadden, S., \& Robinson, A. J. (2017). Numerical simulation of Bridgman solidification of binary alloys. International Journal of Heat and Mass Transfer, 104, 199-211.

https://doi.org/10.1016/j.ijheatmasstransfer.2016.08.030

Link to publication record in Ulster University Research Portal

\section{Published in:}

International Journal of Heat and Mass Transfer

Publication Status:

Published (in print/issue): 31/01/2017

DOI:

10.1016/j.ijheatmasstransfer.2016.08.030

\section{Document Version}

Author Accepted version

\section{General rights}

Copyright for the publications made accessible via Ulster University's Research Portal is retained by the author(s) and / or other copyright owners and it is a condition of accessing these publications that users recognise and abide by the legal requirements associated with these rights.

\section{Take down policy}

The Research Portal is Ulster University's institutional repository that provides access to Ulster's research outputs. Every effort has been made to ensure that content in the Research Portal does not infringe any person's rights, or applicable UK laws. If you discover content in the Research Portal that you believe breaches copyright or violates any law, please contact pure-support@ulster.ac.uk. 


\title{
Numerical Simulation of Bridgman Solidification of Binary Alloys
}

\author{
S. Battaglioli ${ }^{1}$, S. McFadden ${ }^{2}$, A. J. Robinson ${ }^{1}$ \\ ${ }^{1}$ Department of Mechanical and Manufacturing Engineering, Parsons Building, Trinity College Dublin, Ireland \\ ${ }^{2}$ Centre for Engineering and Renewable Energy, Faculty of Computing and Engineering, Magee Campus, Ulster University, \\ BT48 7JL, Northern Ireland
}

\begin{abstract}
A transient 2D axisymmetric numerical model for the Bridgman solidification process for a stationary furnace and moving sample is presented. The model is able to predict the evolution of temperature and solid fraction of binary alloys in cases where buoyancy induced convection is negligible, such as in microgravity conditions. A dimensionless form of the governing equations was derived in order to identify the dimensionless parameters that characterize the process, those being the Stefan, Péclet, and Biot numbers. The problem was solved using a finite volume method and an explicit time stepping scheme. To test the efficacy of the model, simulated results were compared with experimental data from the literature and acceptable agreement was obtained. Finally, a parametric analysis was performed for understanding the influence of the process parameters on solidification. One key feature of this study was the inclusion of a term describing the advection of latent heat due to the translation of the mushy zone with varying solid fraction. This thermal transport mechanism was shown to be significant, since its magnitude was comparable to the advection of sensible heat. It was also found that when small Biot numbers were due to low values of the heat transfer coefficients at the surface of the sample, rather than to small sample radii, advective mechanisms were enhanced resulting in more convex shapes of the liquidus isotherm. This highlighted the importance of considering both axial and radial heat fluxes when describing the process.
\end{abstract}

KEYWORDS: Bridgman furnace, transient solidification, finite volume, binary alloy.

\section{Nomenclature}

\begin{tabular}{|c|c|c|c|}
\hline$A$ & Area & $V$ & Volume \\
\hline$B i$ & Biot number & $\boldsymbol{V}$ & Velocity vector \\
\hline$c_{p}$ & Specific heat capacity & $x$ & Axial coordinate \\
\hline$g_{E}$ & Solid fraction at eutectic temperature & $X$ & Non dimensional axial coordinate \\
\hline$g_{s}$ & Solid fraction & $\alpha$ & Thermal diffusivity \\
\hline$h$ & Heat transfer coefficient & $\theta$ & Non dimensional temperature \\
\hline$H$ & Enthalpy & $\rho$ & Density \\
\hline$k$ & Thermal conductivity & $\tau$ & Non dimensional time \\
\hline$k_{\text {part }}$ & Partition coefficient & & \\
\hline$L$ & Latent heat of fusion & \multicolumn{2}{|c|}{ Subscripts } \\
\hline$P$ & General thermophysical property & cold & Cold heater \\
\hline$P e$ & Péclet number & $c v$ & Control volume \\
\hline$q$ & Heat flux & $E$ & East face of a cv \\
\hline$r$ & Radial coordinate & hot & Hot heater \\
\hline$R$ & Non dimensional radial coordinate & $l$ & Liquid \\
\hline Ste & Stefan number & $N$ & North face of a cv \\
\hline$t$ & Time & $s$ & Solid \\
\hline$T$ & Temperature & $S$ & South face of a cv \\
\hline$T_{E}$ & Eutectic temperature & $W$ & West face of a cv \\
\hline
\end{tabular}




$\begin{array}{ll}T_{L} & \text { Liquidus temperature } \\ T_{M} & \text { Melting temperature } \\ u & \text { Pulling velocity }\end{array}$

\section{Introduction}

The Bridgman-Stockbarger solidification process, originally developed to produce single crystals $[1,2]$, allows for control of directional solidification. Figure 1 shows a simple schematic of a Bridgman furnace where a cylindrical sample is held inside a long and slender crucible. Using a series of controlled coaxial heaters and an adiabatic baffle zone, the material is subjected to a thermal gradient along its length such that the material is fully molten at the hotter end and fully solid at the colder end. As Fig. 1 shows, when samples of binary or multicomponent alloys are considered, a mushy zone (where solid and liquid phases coexist) develops. A relative axial translation, identified as the pulling speed $u$, is imposed between the sample and the furnace either by pulling the crucible from the hot to the cold regions while keeping the furnace stationary or by moving the furnace and keeping the crucible stationary. For typical constant pulling speed operation, steady-state conditions are reached and the solidification process keeps pace with the relative translation speed of the sample. However, the sample will experience initial transient conditions during start-up and stopping periods.
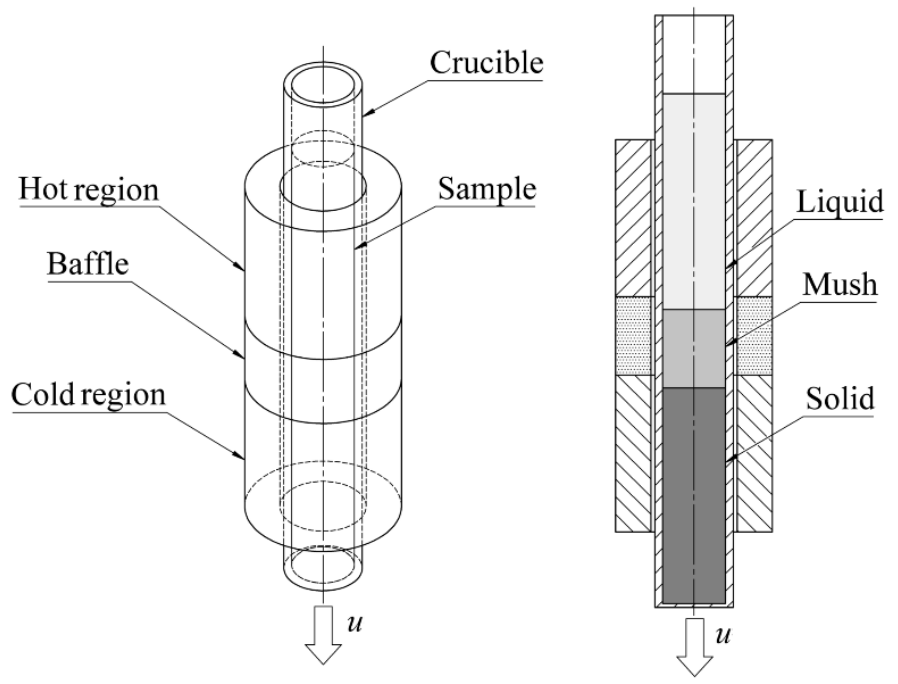

Figure 1: Schematic of a Bridgman furnace.

In steady state operation, the cooling rate of the solidification process can be roughly estimated as the product of the temperature gradient in the axial direction, $G$, and pulling speed, $u$. Accurate information about the temperature gradient may be lacking because the temperature distribution, and hence temperature gradients, change along the length of the sample. In addition, width, shape and position of the mushy zone during the solidification process depend on the temperature distribution to which the sample is subjected. In some processes, much attention is paid to the morphology of the solid-liquid interface. For example, radial temperature gradients can cause a deviation from a planar interface to either a concave or convex ones [3].

In some cases the Bridgman furnace is used in a transient mode of operation. For example, when a phenomenon such as the Columnar to Equiaxed Transition (CET) is investigated, it is necessary to establish transient conditions during the solidification process [4]. In this case, a step change in pulling rate (known as a velocity jump) can cause a CET. In other modes of operation, the Bridgman may use a combination of velocity jump and controlled power down of the heaters to provide the desired transient conditions in the sample [5].

In metallurgical studies, a Bridgman furnace under steady-state operation may be used to determine which conditions are favourable for the formation of different microstructural features in the final casting. For instance, specific steady-state conditions can be related to microstructural characteristics such as primary and secondary 
arm spacing in dendritic growth [6]. In most cases, due to the opaque nature of metal alloys, only a post mortem analysis is possible, whereby the samples are cut, polished, and etched after solidification and then observed by optical or electron microscopy techniques. These types of procedures allow for the direct observation of relevant details, like the final grain structure and size, or the dendritic arm spacing [7-10]. Nevertheless, the observation of some features may still be difficult, as in the case of alloys that experience solid-state phase transformations that may alter or completely remove the initial solidification microstructure [11]. The main disadvantage of post mortem analysis is the lack of time resolved information during the solidification process.

Additional methods may be employed to investigate the solidification phenomenon in real time. X-ray radiographic imaging has been used in some alloy systems to monitor the real-time evolution of the microstructure. However, the applicability of this technique is limited by strict requirements on the sample geometry (thin samples only) and segregation of solute species [12-15]. For example, Reinhart et al. [16] observed CET in a Bridgman furnace in real-time after a velocity jump was imposed on the sample..

Another approach for gathering real-time information during Bridgman solidification is the use of the ultrasonic pulse-echo technique. In this case the time-of-flight of an ultrasonic signal reflected by the solid-liquid interface was measured and used to estimate the velocity of the solidification front $[17,18]$.

For the purpose of gaining accurate insight into the process, practitioners cannot always rely exclusively on experimental results. Therefore, reliable numerical models are valuable, and sometimes necessary tools for analysing alloy solidification. Simulations performed prior to physical experiments may be useful to predict the conditions that the material is likely to encounter during the process. In addition, computational models can be employed during or after the process to extract key information which would be difficult or impossible to observe or measure experimentally.

Nevertheless, it is crucial to highlight that the benefits of adopting numerical methods are highly dependent on the accuracy of the input data, the validity of initial modelling assumptions, and above all, the correctness of the model and solution technique themselves. Hence, when possible, verification and validation of the model are essential steps in establishing the efficacy of the model predictions [19].

Several models for the investigation of the Bridgman solidification process of alloys have been developed in recent years. Timchenko et al. [20,21] implemented a method, based on a single domain enthalpy approach, to study the evolution of temperature, solute concentration and solid-liquid interface during Bridgman solidification of Bi-1at $\% \mathrm{Sn}$. This model assumed furnace configurations with low growth speeds and high thermal gradients, allowing the model to treat the phase change as isothermal and without the formation of any mushy zone between solid and liquid. The simulated solutions showed good agreement with measured experimental results.

Mirihanage et al. [8] employed a front tracking method to simulate the advance of the columnar dendritic front and development of the undercooled region in $\mathrm{Al}-7 \mathrm{wt} . \% \mathrm{Si}$ samples during Bridgman solidification in microgravity. The purpose of this study was to estimate the conditions for CET. Thermal data collected during experiments were used as inputs for the thermal boundary conditions. In the aforementioned models, the relative translation of sample and furnace was treated as a moving boundary condition. As a result, advection was not included in the conservation equations of the model.

A novel Bridgman Furnace Front Tracking Model (BFFTM) was developed by Mooney et al. [5,22-24] where the boundary conditions were fixed and the movement of the sample was modelled by including an additional term in the energy equation for the advection of sensible heat. The model was used to solve an inverse heat transfer problem for the characterization of the heat transfer conditions of a Bridgman furnace using experimental data as inputs [24]. The obtained thermal data were used in a subsequent study to investigate the solidification conditions during a series of experiments [5]. This particular BFFTM was based on a 1D hybrid approach; therefore its applicability was limited to cases when an axial heat flow assumption could be made, requiring that $B i<0.1$.

The overarching objective of this investigation is to investigate the transient evolution of temperature and solid fraction during Bridgman solidification of binary alloys. To this end, a new 2D axisymmetric model is proposed that is capable of capturing both axial and radial heat flow within the cylindrical samples. Microgravity conditions are assumed, therefore buoyancy-induced convection is not considered. This assumption is applicable to practical cases, such as experiments carried out on the International Space Station or on sounding rockets [25] or experiments designed to suppress thermal and solutal convection in the sample [18]. Importantly, the new 2D model also accounts for the advection of latent heat due to the translation of the mushy zone with varying solid fraction within the mushy zone. The specific aims of this investigation are as follows: 
1) to outline the details of a new general dimensional $2 \mathrm{D}$ axisymmetric numerical model for Bridgman solidification of binary alloys

2) to derive a dimensionless form of the equation in order to identify key non-dimensional quantities that influence the evolution of temperature and solid fraction during solidification

3 ) to test the efficacy of the general model by simulating a suitable and relevant experimental test case [18]

4) to perform a parametric analysis of the Bridgman solidification process so as to contribute to the understanding of the influence of different dimensionless parameters on temperature and solid fraction evolution.

\section{Methodology}

\subsection{Mathematical Model}

To obtain the temperature field in the sample, the conservation equations for a mixture of solid and liquid phases must be solved. The general form of these equations is well established and may be found in Bennon and Incropera [26] and $\mathrm{Ni}$ and Incropera[27]. In order to reduce the complexity of the problem, the following assumptions are considered:

- $\quad$ negligible buoyancy induced convection;

- uniform velocity in the domain, equal for the solid and liquid phases ( $\boldsymbol{V}_{s}=\boldsymbol{V}_{l}=$ pulling velocity $u$ );

- constant and uniform density $\rho$ in the sample.

With these assumptions, momentum and continuity equations are automatically satisfied so that it is sufficient to solve only the energy conservation equation. Applying the hypothesis of uniform velocity $u$ to the general mixture energy equation $[27,26]$, it follows:

$$
\frac{\partial H}{\partial t}+u \frac{\partial H}{\partial x}=\nabla \cdot(k \nabla T)
$$

where enthalpy is defined as:

$$
H=\rho \int_{T_{r \varepsilon f}}^{T} c_{p} d T+\rho\left(1-g_{s}\right) L
$$

Therefore, by substituting equation (2) into equation (1), the heat transfer equation written in terms of temperature becomes:

$$
\rho c_{p} \frac{\partial T}{\partial t}=\frac{1}{r} \frac{\partial}{\partial r}\left(r k \frac{\partial T}{\partial r}\right)+\frac{\partial}{\partial x}\left(k \frac{\partial T}{\partial x}\right)+\rho L \frac{\partial g_{S}}{\partial t}-u \rho \frac{\partial\left(c_{p^{T}}\right)}{\partial x}+u \rho L \frac{\partial g_{S}}{\partial x}
$$

Note that $r$ is the radial coordinate and $x$ is the axial coordinate (Figure 2). Since zero gravity conditions are assumed, the orientation of the axial direction is not relevant. The term on the left hand side of this equation represents the rate of change of sensible heat per unit volume. The first and second terms on the right hand side represent the conductive rate of heat flow per unit volume in the radial and axial directions. The third term accounts for the release of latent heat due to the solidification process. The fourth and fifth terms are, respectively, the rate of sensible and latent heat flow per unit volume due to the advection of material at the given pulling velocity $u$. Clearly, the terms that include variations of solid fraction $g_{s}$ are present exclusively in the mushy zone. Hence, these terms are only present in alloy systems that exhibit a mushy zone and are not applicable in the case where there is a sharp interface between liquid and solid regions.

In the context of the past literature, Bridgman solidification of binary alloys under the assumption of negligible buoyancy-induced convection was investigated by Mirihanage et al. [8] and by Mooney et al. [22]. In the case of Mirihanage et al., the relative translation between the sample and the furnace was simulated by applying moving boundary conditions. With the assumption of this reference frame, the effect of advection on solidification was intrinsically included in the boundary conditions hence the two advection terms of equation (3) were not considered in the model. Mooney et al., did model a moving sample, however the last term of equation (3) was not considered, which limits its range of applicability to cases when $c_{p}>>L \cdot\left|\partial g_{s} / \partial T\right|$. Furthermore, this study focussed on scenarios where radial temperature gradients were negligible such that the heat flow throughout the sample could be approximated as 1D. 
In the present study, the reference frame choice of a moving sample in a stationary furnace facilitates for the study of both advection thermal transport mechanisms on the solidification process. Also, the model considers $2 \mathrm{D}$ effects which can be significant with respect to the development of the mushy zone.

In order to solve equation (3), a closure relation for evaluating the evolution of the solid fraction, $g_{s}$, during the process must be included in the model. In the case of binary alloys, the solid fraction may be derived from the Scheil equation as follows [28]:

$$
g_{s}=1-\left(\frac{T_{M}-T}{T_{M}-T_{L}}\right)^{\frac{1}{k_{p_{a r t}-1}}} \quad \text { for } \quad T_{L}<T<T_{E}, \quad 0<g_{s}<g_{E}
$$

where $g_{E}$ is the value of solid fraction at eutectic temperature, calculated by using $T=T_{E}$ in equation (4). Finally, eutectic solidification was assumed to be in equilibrium and was treated using a conservative enthalpy method for isothermal freezing at eutectic temperature $T_{E}$ [29], such that,

$$
g_{s}=1-\frac{H-c_{p} T_{E}}{2} \text { for } T=T_{\bar{E}}, \quad g_{E} \leq g_{s}<1
$$

Specific heat capacity $c_{p}$ and thermal conductivity $k$, in general, change as functions of temperature and are often different for the solid and liquid phases. Depending on the data available for the alloy under consideration, the model can accommodate these thermophysical properties as being either constants or variable. When distinct values for the different phases are available, the general property $P$ in the mushy zone is calculated as follows:

$$
P=\left(1-g_{s}\right) P_{l}+g_{s} P_{s}
$$

where $P_{l}$ and $P_{s}$ may be either constants or polynomial functions of temperature [30].

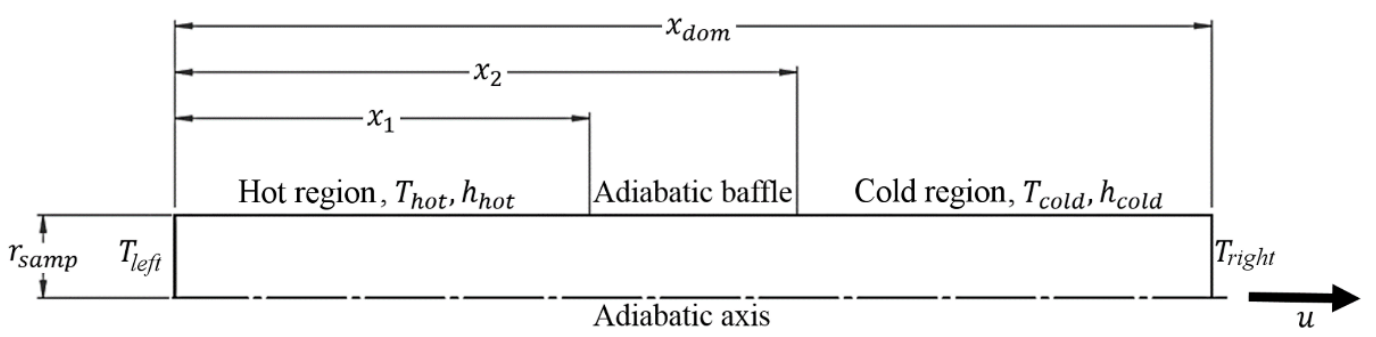

Figure 2: Computational domain for simulations.

Figure 2 shows the computational domain adopted for the simulations. As it is shown, the heat input and heat extraction zones are separated by an adiabatic baffle zone. The total length of the domain is $\mathrm{x}_{\text {dom }}$, while the radius of the cylindrical sample is $r_{\text {samp. }}$.

Since the problem is axisymmetric, half of the axial cross section of the sample was considered and an adiabatic boundary condition was assumed on the axis to enforce symmetry.

Dirichlet boundary conditions were applied at each end of the domain such that,

$$
T(x, r, t)=\left\{\begin{array}{ccl}
T_{\text {left }} & \text { for } & x=0 \\
T_{\text {right }} & \text { for } & x=x_{\text {dom }}
\end{array}\right.
$$

where $T_{\text {left }}$ and $T_{\text {right }}$ could be either constant or variable with time.

To model the radial heat flow at the sample circumference, convective boundary conditions were applied along the interface between the sample and the heaters,

$$
-k \frac{\partial T}{\partial r}\left(x, r_{\text {samp }}, t\right)=\left\{\begin{array}{lll}
h_{\text {hot }}\left(T-T_{\text {hot }}\right) & \text { for } & 0<x<x_{1} \\
h_{\text {cold }}\left(T-T_{\text {cold }}\right) & \text { for } & x_{2}<x<x_{\text {dom }}
\end{array}\right.
$$


where $T_{\text {hot }}$ and $T_{\text {cold }}$ are the temperatures of the hot and cold heaters respectively.

At the interface with the adiabatic baffle, the radial heat flux is zero such that,

$$
\frac{\partial T}{\partial r}\left(x, r_{\text {samp }}, t\right)=0 \quad \text { for } \quad x_{1} \leq x \leq x_{2}
$$

\subsection{Non-dimensional formulation}

In order to perform a parametric study, and to identify the dimensionless numbers that characterize the Bridgman solidification process, a non-dimensional formulation of equation (3) was derived. For this purpose, the following dimensionless variables are defined:

$$
X=\frac{x}{l_{r \varepsilon f}} ; \quad R=\frac{r}{l_{r \varepsilon f}} ; \quad \theta=\frac{\tau}{\Delta T_{r \varepsilon f}} ; \quad \tau=\frac{\alpha t}{l_{r \varepsilon f}^{2}}
$$

where $\alpha=k /\left(\rho c_{p}\right)$ is the thermal diffusivity, and $l_{\text {ref }}$ and $\Delta T_{\text {ref }}$ are the length and temperature reference scales respectively. By substituting these quantities into equation (3), a new dimensionless formulation for the energy equation is obtained:

$$
\frac{\partial \theta}{\partial \tau}=\frac{1}{R} \frac{\partial}{\partial R}\left(R \frac{\partial \theta}{\partial R}\right)+\frac{\partial^{2} \theta}{\partial X^{2}}+\frac{1}{S t e} \frac{\partial g_{5}}{\partial \tau}-P e \frac{\partial \theta}{\partial X}+\frac{P \theta}{S t e} \frac{\partial g_{5}}{\partial X}
$$

Note that, for the derivation of equation (11), all the thermophysical properties were considered constant. Here, two dimensionless numbers are identified, the Péclet number and Stefan number:

$$
P e=\frac{u_{r \varepsilon f}}{\alpha} ; \quad S t e=\frac{c_{p} \Delta T_{r \varepsilon f}}{2}
$$

From a physical point of view, the first parameter represents the relative magnitude of convective and diffusive transport of heat, whereas the second parameter represents the ratio of sensible and latent heat. In order to assign a meaningful value to the Stefan number for a eutectic alloy, the difference between the liquidus and eutectic temperatures of the alloy under consideration was used to define the reference temperature scale: $\Delta T_{\text {ref }}=T_{L}-$ $T_{E}$.

It is also noticed that the axial variation of solid fraction is proportional to the ratio Pe/Ste. This quantity may be rewritten as follows,

$$
\frac{\mathrm{P}_{e}}{S t e}=\frac{\frac{u l_{r \& f}}{\alpha}}{\frac{c_{p} T_{r \& f}}{L}}=\frac{\frac{\rho u L}{L_{r \& f}}}{\frac{k \Delta T_{r \& f}}{l_{r \& f}^{2}}} \sim \frac{\text { convective latent heat transport }}{\text { diffusive heat transport }}
$$

Therefore this dimensionless quantity has the same meaning as the Péclet number, in the sense that it represents the relative magnitude of conductive to advective heat transport, though for this instance it is latent heat advection opposed to that of sensible heat.

The dimensionless formulation of equations (3)-(9) was obtained in an analogous way; in particular, the convective condition expressed in equation (8) becomes:

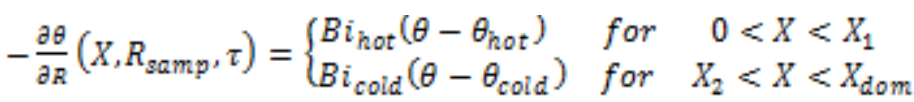

In doing so a third dimensionless number is identified, the Biot number $B i$, defined as,

$$
B i=\frac{n l_{r \varepsilon f}}{k}
$$


This quantity represents the relative magnitude of the diffusion resistance inside the sample and the convective resistance at the surface of the sample. To characterize the value of $B i$ along with the other dimensionless parameters the reference length scale was chosen as the ratio between the volume and the external surface where the heat transfer is occurring. Thus, for the cylindrical domain under consideration, the reference length scale is $l_{\text {ref }}=r_{\text {samp }} / 2$ as is common for radial systems.

\subsection{Numerical Model}

A finite volume numerical model was implemented for solving the problem outlined above. Here, the model for the non-dimensional formulation is described. The cylindrical computational domain was divided into annular control volumes of length $\Delta x$ and thickness $\Delta r$, as shown in Figure 3. For practical purposes, related to the performance of a grid convergence study, half control volumes were considered at the boundaries.

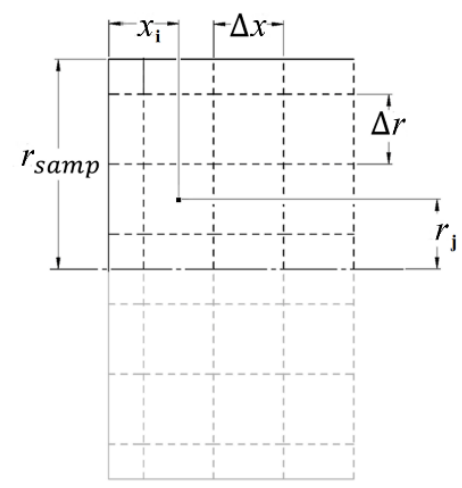

Figure 3: Domain discretization.

Using an explicit formulation in time, the temperature at the centre of a general control volume $(i, j)$ at the new time step, given by the discretized heat equation (3), is:

$$
\begin{aligned}
& T_{i, j}^{n e w}=T_{i, j}+\frac{\Delta t}{\rho c_{p_{i, j}}}\left\{\frac{1}{v_{c v_{i, j}}}\left[\left(A_{s_{i, j}} q_{s_{i, j}}+A_{n_{i, j}} q_{n_{i, j}}\right)+\left(A_{w_{i, j}} q_{w_{i, j}}+A_{\varepsilon_{i, j}} q_{e_{i, j}}\right)\right]-u \rho \frac{\left(c_{v_{a_{i, j}}} T_{\varepsilon_{i, j}}-c_{p_{w_{i, j}}} T_{w_{i, j}}\right)}{\Delta X}+\right. \\
& \left.u \rho L \frac{\left(g_{s_{i, j}}-g_{s_{w i, j}}\right)}{\Delta x}+\rho L \frac{\left(g_{s_{i, j}}^{n a w}-g_{s_{i, j}}\right)}{\Delta t}\right\}
\end{aligned}
$$

where the volume and faces of each control volume are calculated as follows:

$$
\begin{array}{rr}
V_{C V_{i, j}}=2 \pi r_{j} \Delta \mathrm{r} \Delta x ; & A_{w_{i, j}}=A_{e_{i, j}}=2 \pi r_{j} \Delta r ; \\
A_{s_{i, j}}=2 \pi\left(r_{j}-\frac{\Delta r}{2}\right) \Delta x ; & A_{n_{i, j}}=2 \pi\left(r_{j}+\frac{\Delta r}{2}\right) \Delta x
\end{array}
$$

The quantities $q_{s}, q_{n}, q_{w}$, and $q_{e}$ are the heat fluxes at the faces of each control volume such that:

$$
\begin{array}{rlrl}
q_{s_{i, j}} & =k_{i, j_{s}} \frac{\left(\tau_{i, j-1}-\tau_{i, j}\right)}{\Delta r} ; & q_{n_{i, j}}=k_{i, j_{n}} \frac{\left(\tau_{i, j+1}-\tau_{i, j}\right)}{\Delta r} ; \\
q_{w_{i, j}}=k_{i, j_{w}} \frac{\left(\tau_{i-1, j}-\tau_{i, j}\right)}{\Delta x} ; & q_{e_{i, j}}=k_{i, j_{2}} \frac{\left(\tau_{i+1, j}-\tau_{i, j}\right)}{\Delta x}
\end{array}
$$

The values of the thermophysical properties at the $\mathrm{CV}$ faces were calculated as harmonic means of the values at their respective centres [31]. The model adopted is explicit in time so that all the terms on the right hand side of equation (16) refer to the previous time step, except for the new value for solid fraction $g_{s}{ }^{\text {new }}$, given by the discretization of the time derivative of solid fraction in equation (3). To calculate this term, a Newton-Raphson iteration method was employed at each time step, similar to that described in [29]. This was required because the solid fraction is expressed by the Scheil equation (4) which is a nonlinear function of temperature. The numerical scheme for the solution of the dimensionless form of the equation is analogous and its derivation straightforward so is not discussed here for conciseness. 
As an initial condition for the temperature distribution in the sample, an arbitrary piece-wise linear function was defined as follows:

$$
T(x, r, 0)= \begin{cases}T_{\text {left }} & \text { for } \quad 0<x<x_{1} \\ \left(T_{\text {left }}-T_{\text {right }}\right) \frac{\left(x-x_{2}\right)}{\left(x_{1}-x_{2}\right)}+T_{\text {right }} & \text { for } \quad x_{1} \leq x \leq x_{2} \\ T_{\text {right }} & \text { for } \quad x_{2}<x<x_{\text {dom }}\end{cases}
$$

In order to obtain a physically realistic distribution of temperature within the sample, during the first stage of the simulations the pulling velocity $u$ was set to zero. The first stage lasted until temperature and solid fraction distribution settled to a steady-state solution. After this condition was reached, a velocity jump was applied to the sample.

\subsection{Conditions for comparison with experimental data}

In order to verify the efficacy of the model and solution technique, simulations were compared with data from experiments performed by Zimmerman et al. [18]. In the experiments, directional Bridgman solidification of Al$1.3 \mathrm{wt} \% \mathrm{Cu}$ cylindrical samples was performed. Three thermocouples were used to measure temperature evolution during the process and an ultrasonic pulse-echo technique was employed to determine the growth rate. Importantly, the availability of time-dependent measurements makes this experiment particularly suitable for the comparison with the transient model developed in this work. It is important to note that in the experiments the sample was stationary while the furnace was translated. On the contrary, the model simulates a moving sample in a stationary furnace. Nevertheless, since the pulling velocity was constant it is possible to compare the result by considering the simple relation $x=u \cdot t$.

Table 1 shows the set-up parameters used for the comparisons. Several simulations were performed, with different heat transfer coefficients, since their precise measurements were not available. $h_{\text {hot }}$ and $h_{\text {cold }}$ were varied in a realistic range of values (last two columns of Table 1) for Bridgman furnaces within an argon atmosphere based on the literature [32,33].

Table 1: Set-up for comparison with experimental data from Zimmermann et al., 2007.

\begin{tabular}{cccccccc}
\hline$x_{\text {dom }}[\mathrm{m}]$ & baffle length $[\mathrm{m}]$ & $r_{\text {samp }}[\mathrm{m}]$ & $u[\mathrm{~m} / \mathrm{s}]$ & $T_{\text {left }}=T_{\text {hot }}\left[{ }^{\circ} \mathrm{C}\right]$ & $T_{\text {right }}=T_{\text {cold }}\left[{ }^{\circ} \mathrm{C}\right]$ & $h_{\text {hot }}\left[\mathrm{W} /\left(\mathrm{m}^{2}{ }^{\circ} \mathrm{C}\right)\right]$ & $h_{\text {cold }}\left[\mathrm{W} /\left(\mathrm{m}^{2}{ }^{\circ} \mathrm{C}\right)\right]$ \\
\hline 0.2 & 0.04 & $4 \cdot 10^{-3}$ & $2 \cdot 10^{-6}$ & 1100 & 25 & {$[100,350]$} & {$[20,50]$} \\
\hline
\end{tabular}

\subsection{Conditions for the parametric study}

A parametric study was carried out simulating the Bridgman solidification process for a range of conditions aimed to gain knowledge with respect to the relative influence of each of the important dimensionless parameters, along with several key aspects of the solidification process, such as the temperature evolution, shape of the mushy zone and its position in the furnace.

The parametric study was performed by considering only variations corresponding to physically realistic scenarios. Here, the length of the domain $x_{d o m}$ and the length and temperatures of the heaters were maintained constant and the same sample material was used for all the simulations, such that the thermophysical properties, and hence Ste, were constant.

The upper part of Table 2 reports the dimensional input data used in the study, while the bottom part shows the relevant dimensionless quantities relative to each simulation. An arbitrary reference set-up (simulation S0) was selected and the following cases were considered:

- $\quad$ samples with different radii (simulations S1 and S2): $X_{d o m}, P e$ and Bi change at the same time; 
- different pulling velocities (simulations S3 and S4): only Pe changes;

- different heat transfer coefficients (simulations S5 and S6): only Bi changes.

Table 2: Input values for parametric simulations.

\begin{tabular}{|c|c|c|c|c|c|c|c|c|}
\hline $\begin{array}{l}\text { Simulation } \\
\text { Run }\end{array}$ & $x_{\text {dom }}[\mathrm{m}]$ & $x_{l}[\mathrm{~m}]$ & $x_{2}[\mathrm{~m}]$ & $T_{\text {left }}=T_{\text {hot }}\left[{ }^{\circ} \mathrm{C}\right]$ & $T_{\text {right }}=T_{\text {cold }}\left[{ }^{\circ} \mathrm{C}\right]$ & $r_{\text {samp }}[\mathrm{m}]$ & $u[\mathrm{~m} / \mathrm{s}]$ & $h\left[\mathrm{~W} /\left(\mathrm{m}^{2}{ }^{\circ} \mathrm{C}\right)\right]$ \\
\hline So & 0.2 & 0.09 & 0.11 & 668 & 527 & 0.02 & $0 \rightarrow 0.5 \cdot 10^{-3}$ & 1000 \\
\hline $\begin{array}{l}\text { S1 } \\
\text { S2 }\end{array}$ & 0.2 & 0.09 & 0.11 & 668 & 527 & $\begin{array}{l}0.01 \\
0.04\end{array}$ & $0 \rightarrow 0.5 \cdot 10^{-3}$ & 1000 \\
\hline $\begin{array}{l}\text { S3 } \\
\text { S4 }\end{array}$ & 0.2 & 0.09 & 0.11 & 668 & 527 & 0.02 & $\begin{array}{c}0 \rightarrow 0.25 \cdot 10^{-3} \\
0 \rightarrow 1.0 \cdot 10^{-3}\end{array}$ & 1000 \\
\hline \multirow[t]{2}{*}{$\begin{array}{l}\text { S5 } \\
\text { S6 }\end{array}$} & 0.2 & 0.09 & 0.11 & 668 & 527 & 20 & $0 \rightarrow 0.5 \cdot 10^{-3}$ & $\begin{array}{c}500 \\
2000\end{array}$ \\
\hline & \multicolumn{2}{|c|}{$X_{d o m}$} & \multicolumn{2}{|r|}{$R_{\text {samp }}$} & Ste & \multicolumn{2}{|c|}{$P e$} & $B i$ \\
\hline So & \multicolumn{2}{|c|}{20} & \multicolumn{2}{|r|}{2} & 0.211 & \multicolumn{2}{|c|}{$0 \rightarrow 0.1686$} & 0.1250 \\
\hline $\begin{array}{l}\text { S1 } \\
\text { S2 }\end{array}$ & \multicolumn{2}{|c|}{$\begin{array}{l}40 \\
10\end{array}$} & \multicolumn{2}{|r|}{2} & 0.211 & \multicolumn{2}{|c|}{$\begin{array}{l}0 \rightarrow 0.0843 \\
0 \rightarrow 0.3372\end{array}$} & $\begin{array}{l}0.0625 \\
0.2500\end{array}$ \\
\hline $\begin{array}{l}\text { S3 } \\
\text { S4 }\end{array}$ & \multicolumn{2}{|c|}{20} & \multicolumn{2}{|r|}{2} & 0.211 & \multicolumn{2}{|c|}{$\begin{array}{l}0 \rightarrow 0.0843 \\
0 \rightarrow 0.3372\end{array}$} & 0.1250 \\
\hline $\begin{array}{l}\text { S5 } \\
\text { S6 }\end{array}$ & \multicolumn{2}{|c|}{20} & \multicolumn{2}{|r|}{2} & 0.211 & \multicolumn{2}{|c|}{$0 \rightarrow 0.1686$} & $\begin{array}{l}0.0625 \\
0.2500\end{array}$ \\
\hline
\end{tabular}

Table 3 lists the thermophysical properties of the alloys used in the comparison with experimental data and in the parametric study. Al-1.3wt\%Cu was the alloy used by Zimmerman et al. in the experiments [18], and hence used in the comparison.

The material considered for the parametric study was Al-7wt $\% \mathrm{Si}$. This alloy was selected both due to the availability of data in the literature and for its solidification behaviour. In fact, at eutectic temperature, the solid fraction is equal to 0.5417 which means that half of the solidification process occurs over a wide range of temperatures $\left(T_{L}-T_{E}=41^{\circ} \mathrm{C}\right)$. As such, a wide mushy zone develops during solidification. This characteristic is particularly suitable for observing the influence of the process parameters on this region.

Table 3: Thermophysical properties of Al-1.3wt\% Cu and Al-7wt\%Si used in simulations.

\begin{tabular}{|c|c|c|c|}
\hline & \multicolumn{2}{|c|}{$\mathrm{Al}-1.3 \mathrm{wt} \% \mathrm{Cu}$} & \multirow{2}{*}{$\mathrm{Al}-7 \mathrm{wt} \% \mathrm{Si}$} \\
\hline & Solid & Liquid & \\
\hline$T_{M}\left[{ }^{\circ} \mathrm{C}\right]$ & \multicolumn{2}{|c|}{660.2} & 660.2 \\
\hline$T_{L}\left[{ }^{\circ} \mathrm{C}\right]$ & \multicolumn{2}{|c|}{657} & 618 \\
\hline$T_{E}\left[{ }^{\circ} \mathrm{C}\right]$ & \multicolumn{2}{|c|}{547} & 577 \\
\hline$k_{\text {part }}$ & \multicolumn{2}{|c|}{0.17} & 0.13 \\
\hline$c_{p}\left[\mathrm{~J} /\left(\mathrm{kg} \cdot{ }^{\circ} \mathrm{C}\right)\right]$ & 2396 & 496 & 1100 \\
\hline$k\left[\mathrm{~W} /\left(\mathrm{m} \cdot{ }^{\circ} \mathrm{C}\right)\right]$ & 209 & 90.7 & 80 \\
\hline$\rho\left[\mathrm{kg} / \mathrm{m}^{3}\right]$ & \multicolumn{2}{|c|}{2500} & 2452.5 \\
\hline$\rho L\left[\mathrm{~J} / \mathrm{m}^{3}\right]$ & \multicolumn{2}{|c|}{$961 \cdot 10^{6}$} & $1064 \cdot 10^{6}$ \\
\hline
\end{tabular}

3. Results and discussion

This section reports and discusses the results of the comparison with experimental data and of the parametric investigation. In all simulations the domain was divided into annular control volumes of length $\Delta x=1 \mathrm{~mm}$ and thickness $\Delta r=1 \mathrm{~mm}$. The time step used in the simulations was equal to 0.001 seconds, which ensured the 
stability of the explicit scheme employed. Grid and time step independence for this choice were investigated and the numerical model was proven to be convergent. The estimated L2 norm of the truncation error due to the discretization was of the order of $0.1{ }^{\circ} \mathrm{C}$. It should be noted that a code-to-code verification exercise was performed with this model by comparing it with a commercial code. The details of this numerical verification are provided elsewhere [34].

\subsection{Comparison with experimental data}

Due to the complex nature of the solidification process under consideration, there does not yet exist benchmark experimental data that can be leveraged to validate numerical simulations in accordance with established validation criteria [35]. As a result, relevant measurements from the literature have been used which means that the analysis cannot be regarded as a rigorous validation exercise, since the experiments do not provide all of the relevant data to reproduce exactly the same conditions. Regardless, the data provided from the experiments are sufficient to establish the veracity of the simulations provided that any assumptions, such as the magnitudes of the heat transfer coefficients, are within acceptable limits. Albeit adjustable parameters, there are established ranges for their magnitudes and, for the scenario under consideration here, adequate agreement was found when $h_{\text {hot }}=300 \mathrm{~W} /\left(\mathrm{m}^{2} \cdot{ }^{\circ} \mathrm{C}\right)$ and $h_{\text {cold }}=40 \mathrm{~W} /\left(\mathrm{m}^{2} \cdot{ }^{\circ} \mathrm{C}\right)$ which are acceptable values based on the literature $[32,33]$.

Figure 4 shows the cooling curve measured during the experiments by thermocouples at steady state during the pulling stage. This is compared with the computed cooling curve at steady state after the velocity jump. The time scale is normalised to the time where the temperature was equal to the equilibrium solidus temperature of $\mathrm{Al}-1.3 \mathrm{wt} \% \mathrm{Cu}$, which in this case is $627.5^{\circ} \mathrm{C}$. The experimental cooling rates were about $34 \times 10^{-3} \mathrm{~K} / \mathrm{s}$ in the liquid and $20 \times 10^{-3} \mathrm{~K} / \mathrm{s}$ in the solid. In the simulations, similar results were obtained, with cooling rates of $33 \times 10^{-3} \mathrm{~K} / \mathrm{s}$ in the liquid and $16 \times 10^{-3} \mathrm{~K} / \mathrm{s}$ in the solid.

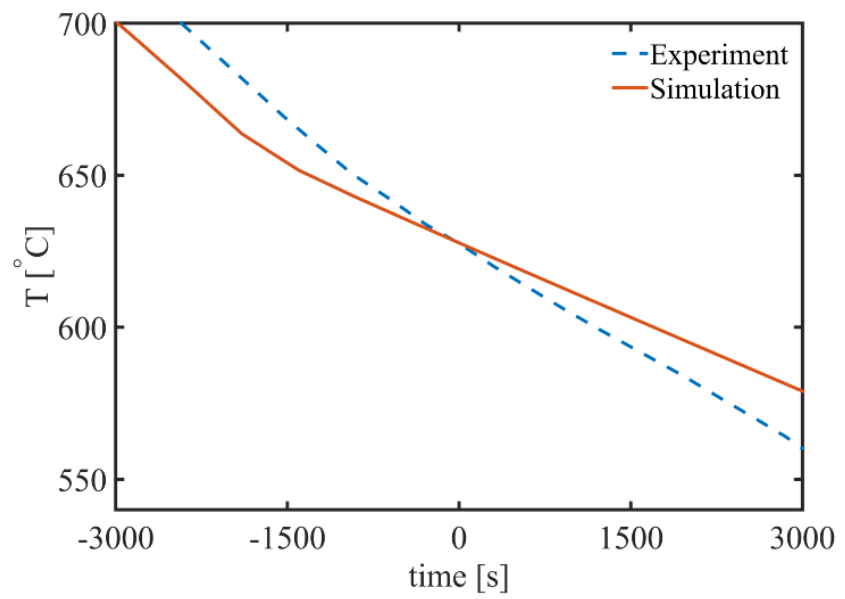

Figure 4: Measured and computed cooling curves at steady state, normalised to the time where the temperature equals the solidus temperature of the alloy in thermal equilibrium $\left(627.5^{\circ} \mathrm{C}\right)$.

Figure 5 shows the temperature gradient obtained from the difference of temperatures measured by two thermocouples located $16 \mathrm{~mm}$ and $10 \mathrm{~mm}$ above the measured solid-liquid interface at the beginning of the pulling stage. Since the numerical model reproduces the actual formation of a mushy zone, instead of a sharp solid-liquid interface, the simulated temperature gradient in Figure 5 was calculated as the difference of temperatures between two points located $16 \mathrm{~mm}$ and $10 \mathrm{~mm}$ ahead of the mid-point of the mushy zone. Time $t=0 \mathrm{~s}$ corresponds to the beginning of the pulling stage when the velocity jump was imposed. 


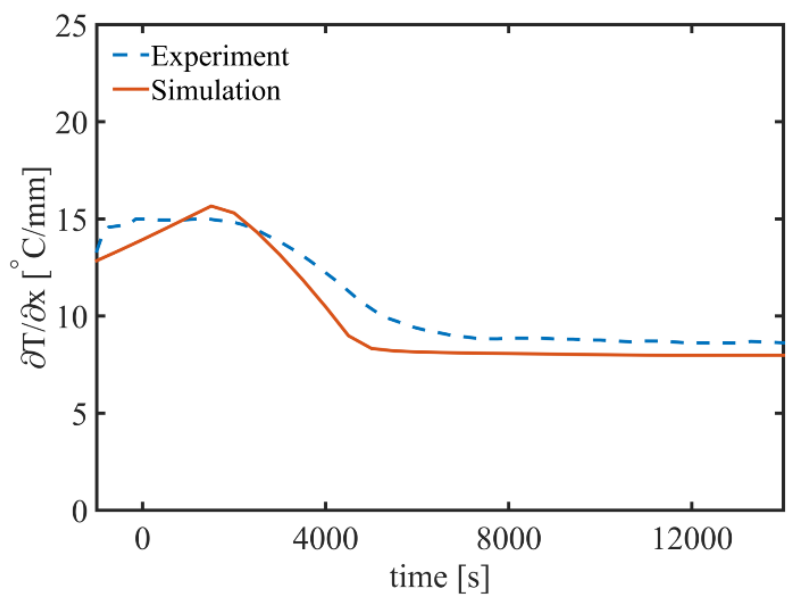

Figure 5: Axial temperature gradient taken from the temperature difference measured by two thermocouples and temperature gradient from simulations; time is normalised to the beginning of the pulling stage.

In general, the simulation results show qualitative agreement with experimental data from Zimmermann et al. [18]. Nevertheless, some differences are present. These differences could be due to several reasons. For example, the values of the heat transfer coefficients at the circumference were chosen in a realistic range for an argon atmosphere furnaces, but the actual values from the experiments were unavailable. Also, in reality the heat transfer coefficients may vary with axial position, while in the simulations constant values of $h_{\text {cold }}$ and $h_{\text {hot }}$ were assumed. In addition, for the Dirichlet boundary condition at the right and left ends of the sample, constant temperatures were assumed, since precise measurements of real temperatures from thermocouples were not available. Nonetheless, the agreement between the simulations and experiments was deemed to be acceptable, especially considering the uncertainty in the experimental data. In particular, Figure 5 shows good agreement, demonstrating that the model was capable of effectively reproducing the axial temperature gradient.

Since the pulling velocity was very low $\left(u=2 \cdot 10^{-6} \mathrm{~m} / \mathrm{s}\right)$, and with respect to the resolution of the grid $(\Delta x=\Delta r=1$ $\mathrm{mm}$ ), it was not possible to observe a transient in the shape and position of the mushy zone envelope in the simulations for this test scenario. However, it was possible to detect the duration of the transient phase by calculating the difference of temperature at subsequent time steps. The total duration of the transient stage was similar to the one measured in [18]. During the experiments the transient stage lasted about 500 seconds while in the simulations a full steady-state condition was reached after about 530 seconds which is deemed to be acceptable agreement.

Based on the verification work [34] and the validation attempt against the relevant but limited experimental data, it is believed that the model is sufficiently accurate that it can be used to provide correct physical insight into the influence of physical parameters on the Bridgman solidification process.

\subsection{Influence of varying $P e$ and $B i$ on Bridgman solidification}

The dimensionless parameters that characterize the Bridgman solidification process are the Stefan number Ste, Péclet number $P e$, and Biot number $B i$. Ste is defined as $c_{p} \cdot \Delta T_{r e f} / L$. In the present work, the temperature range is defined as $\Delta T_{r e f}=T_{L}-T_{E}$. Hence Ste represents the ratio of sensible and latent heat released across the temperature range where solidification occurs, i.e., in the range of temperature where a mushy zone exists. With this choice, Ste is exclusively a function of the sample material properties and is not a variable process parameter. Hence variations in Ste were not characterized explicitly in the parametric study since only one alloy, Al-7wt\%Si, was considered. That is not to say that its influence is not considered since the ratio Pe/Ste defines the order of magnitude of the advection of latent heat, which is a key parameter under investigation in this work. On the other hand, $P e$ and $B i$ are functions of the material properties as well as of process parameters such as pulling velocity, dimension of the sample and furnace heat transfer coefficients. Therefore, their variations were considered explicitly in the parametric study.

In the discussion, particular emphasis is placed on the evolution of the envelope of the mushy zone on the liquid side, corresponding to the liquidus isotherm $\left(T=618^{\circ} \mathrm{C}\right)$. In fact, depending on the magnitude of axial and radial 
heat fluxes at locations close to the liquidus isotherm, the development of different grain structures in front of the axial columnar grains which usually constitute the mushy zone in Bridgman processes could be promoted, i.e. radial columnar or equiaxed grains. In particular, previous studies [5] suggest that negative radial thermal gradients close to this position could promote the growth of radial columnar grains, while this radial growth would be suppressed by positive radial thermal gradients.

As mentioned earlier, the last two terms of the heat equation (11) describe the thermal transport by advection and are functions of Ste and/or $P e$. In particular, the term that expresses the transport of sensible heat by advection is directly proportional to $P e$, while the last term representing the transport of latent heat by advection is proportional to the ratio $P e / S t e$. From Table 2, Ste $=0.211$, while $P e$ ranges between 0.0843 and 0.3372 , such that $0.4<P e / S t e<1.6$. From a scaling point of view, one would thus expect the latter to be the dominant advection mechanism in the mushy zone i.e. within the region between the liquidus isotherm and the eutectic isotherm where the solid fraction is varying. To demonstrate the relative influence of each advection term, Figure 6 shows the temperature distribution along the axial axis of the sample both with and without advection terms, for the baseline simulation S0. In one case, advection is assumed to be absent by setting $u=0$. Advection of sensible heat only, as well as the case whereby advection of both sensible and latent heat together, are also simulated for comparison. It is clear that the steady state temperatures for the $P e>0$ cases are higher when the terms describing the advection of both sensible and latent heat are included. In particular, the inclusion of the advetion of latent heat has a significantly higher impact on the temperature distribution, highlighting it as the dominant advection mechanism which is consistent with the scaling argument posed above.

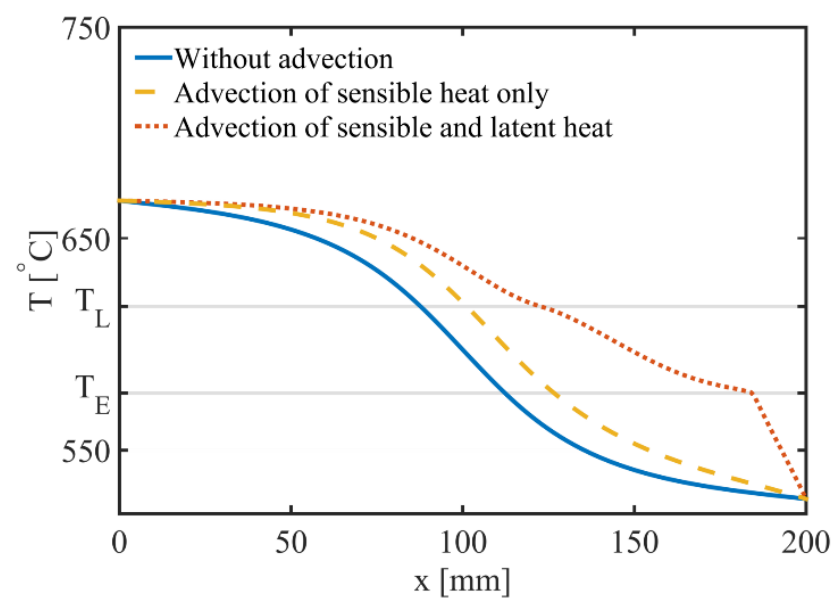

Figure 6: Simulation S0: temperature distribution on the axis of the sample, obtained with and without advection. 

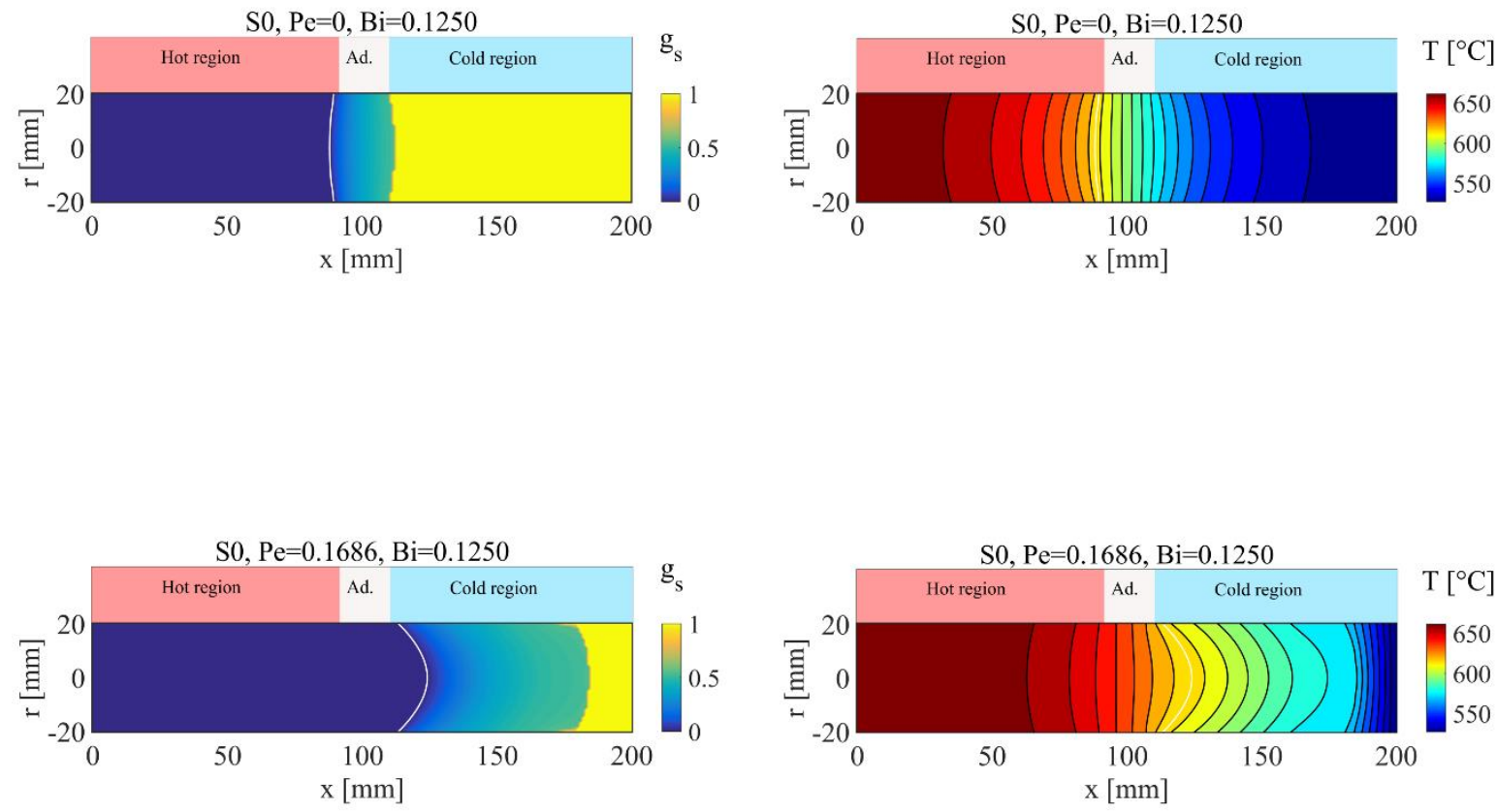

Figure 7: Simulation S0: solid fraction and temperature distribution in an axial section of the sample. (Top) resting stage $(P e=0),(B o t t o m)$ pulling stage $(P e>0)$. The white highlights the position of the liquidus isotherm, which represents the envelope of the mushy zone on the liquid side.

Figure 7 shows the distribution of solid fraction and temperature in a cross section of the sample for the baseline simulation S0. The top images represent the steady state solution in the resting stage $(P e=0)$, while the bottom images are the steady state solution reached during the pulling stage $(P e>0)$ and correspond with the upper and lower curves in Figure 6 for reference. As it is shown, when the pulling velocity is zero the mushy zone is located within the adiabatic zone i.e. $90 \mathrm{~mm} \leq x \leq 110 \mathrm{~mm}$. In this case, the liquidus isotherm is located marginally inside the left hand heat source side of the domain. Here, heat flows inward to the material from the heat source along its circumference such that $\partial T / \partial r>0$ and the liquidus assumes a corresponding concave shape. Heat transfer from the heat source region to the heat sink region is thus predominantly axial, across the thin mushy zone, resulting in the steep temperature gradient observed in Figure 8. Once steady state is achieved subsequent to the velocity jump $(P e>0)$, the mushy zone moves to the right penetrating deep into the low temperature heat sink region. In contrast to the $P e=0$ case, the liquidus isotherm is now positioned within the heat sink region. Thermal access to the cold heat sink walls causes $\partial T / \partial r<0$ for the entire mushy zone resulting in a convex liquidus isotherm. The figure also shows a substantially lengthened mushy zone, to the point that it occupies a significant portion of the heat sink domain. Latent heat is being released within this region, acting as a volumetric heat source term. Generation and advection of latent heat cause the higher temperatures over the mushy zone compared with the $P e=0$ case, as shown clearly in Figure 6 . There is also a prominant and almost discontinuous increase in the magnitude of the temperature gradient near the end of the heat sink region, which occurs after the end of the mushy zone $\left(T=T_{E}\right)$. This is due to the fact that the latent heat terms, whose magnitude is particularly high in correspondence to the eutectic zone where the solid fraction gradient is higher, drop abruptly to zero in the solid zone.. Thus, the inclusion of advection, in particular for this case that of latent heat, has a significant influence on the heat transfer within the system, especially in the region where the solid fraction is varying. As will be discussed, advection and 2D effects are coupled and can influence the heat transfer and solidification mechanics, as is represented in Figure 8 which shows a wide variation of the shape of the liquidus isotherms $\left(T=618^{\circ} \mathrm{C}\right)$ from each simulation listed in Table 2 for the steady state pulling stage. 


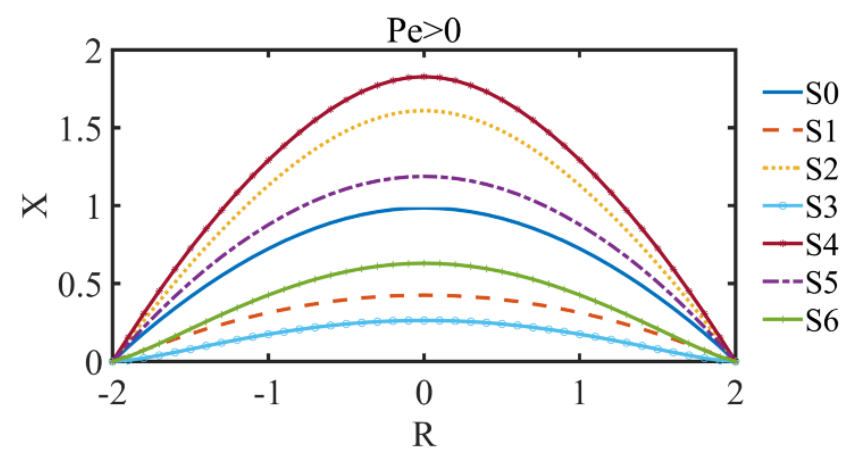

Figure 8: Curvature of the liquidus isotherm $\left(T=618^{\circ} \mathrm{C}\right)$ at steady state in the pulling stages; note that both axes are dimensionless.
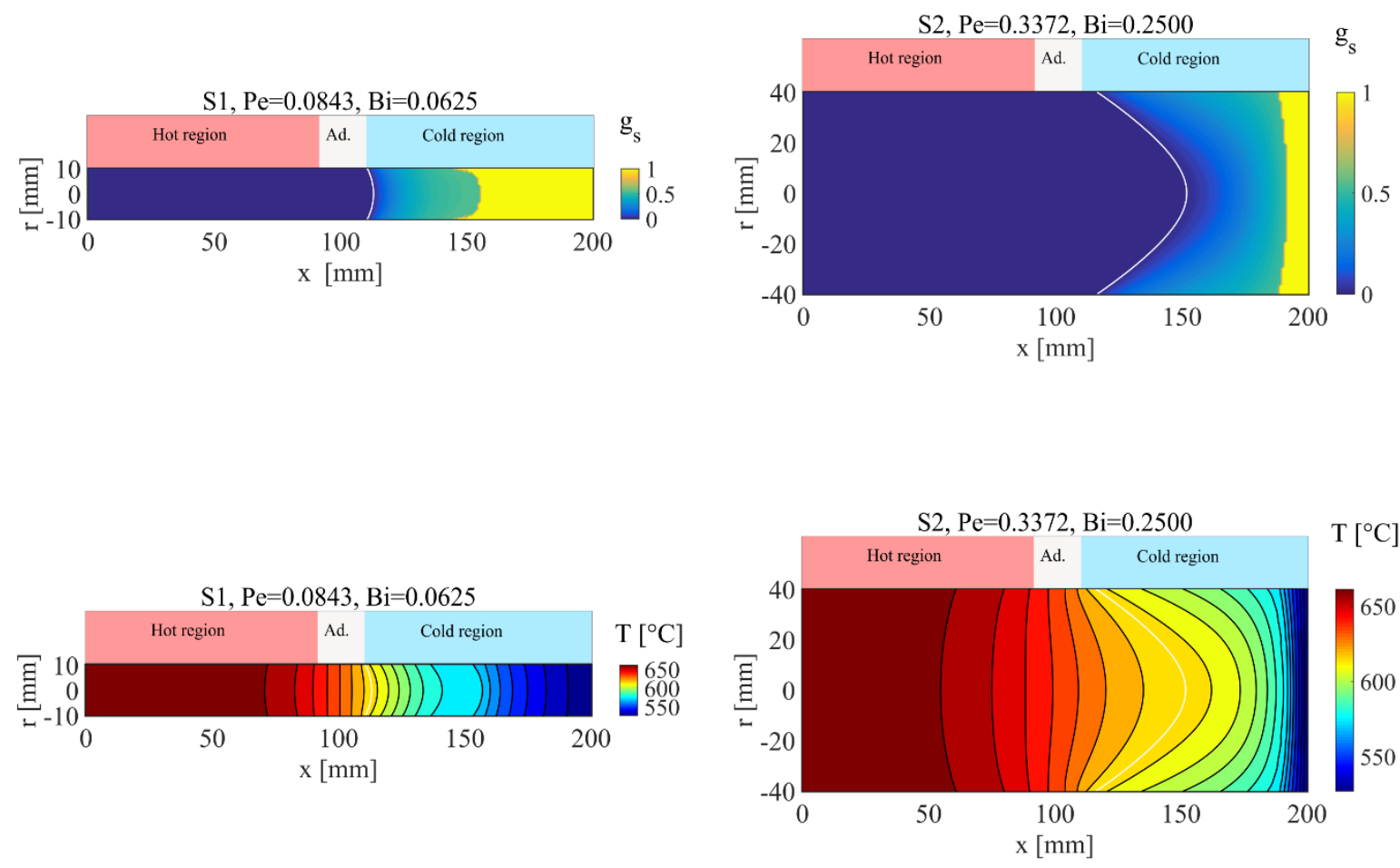

Figure 9: Simulations S1(left) and S2 (right) showing solid fraction (top) and temperature distribution (bottom) in an axial section of the samples during the pulling stage $(\mathrm{Pe}>0)$.

Figure 9 shows the steady state solution of solid fraction (top) and temperature (bottom) during the pulling stage for simulations $\mathrm{S} 1$ and $\mathrm{S} 2$, corresponding to $\mathrm{Bi}=0.0625 \& \mathrm{Pe}=0.0843$ and $\mathrm{Bi}=0.25 \& \mathrm{Pe}=0.3372$ respectively. When the radius is smaller $(\mathrm{S} 1) \mathrm{Bi}$ is also lower due to a reduction in the scale of the radial conductive thermal resistance within the sample. Compared with S2, the overall radial thermal gradients of S1 are expectedly weaker and the curvatures of the isotherms are notably smaller along the entire domain. In this comparison, $P e$ is also small for $\mathrm{S} 1$, so that advection is weak compared with thermal diffusion. Albeit weak, it is still sufficient to influence the position of the mushy zone such that it is located inside the cold heat sink region with the liquidus positioned just outside of the adiabatic zone. Being inside the heat sink zone, heat is 
transferred both axially and radially which influenced the breadth of the mushy zone and curvature of the liquidus isotherm, showing low yet noticeable positive curvature in Figure 8. In comparison, by increasing the radius (S2) the radial component of the conductive thermal resistance increases, increasing $B i$, while at the same time the effect of advection becomes stronger by the increase in $P e$. The former reduces the scale of radial conduction while the latter increases the scale of advection causing the mushy zone to penetrate deeper into the colder heat sink region. These two effects compound in such a way as to induce strong radial heat flow, including significantly more pronounced curvature of the liquidus isotherm, as seen in Figure 8. For later reference, it is also worth noting that both $B i$ and $P e$ are directly proportional to the value of the sample radius, hence when $r_{\text {samp }}$ changes the ratio $\mathrm{Bi} / \mathrm{Pe}$ as well as $\mathrm{Bi} /(\mathrm{Pe} / \mathrm{Ste})$ remain constant.
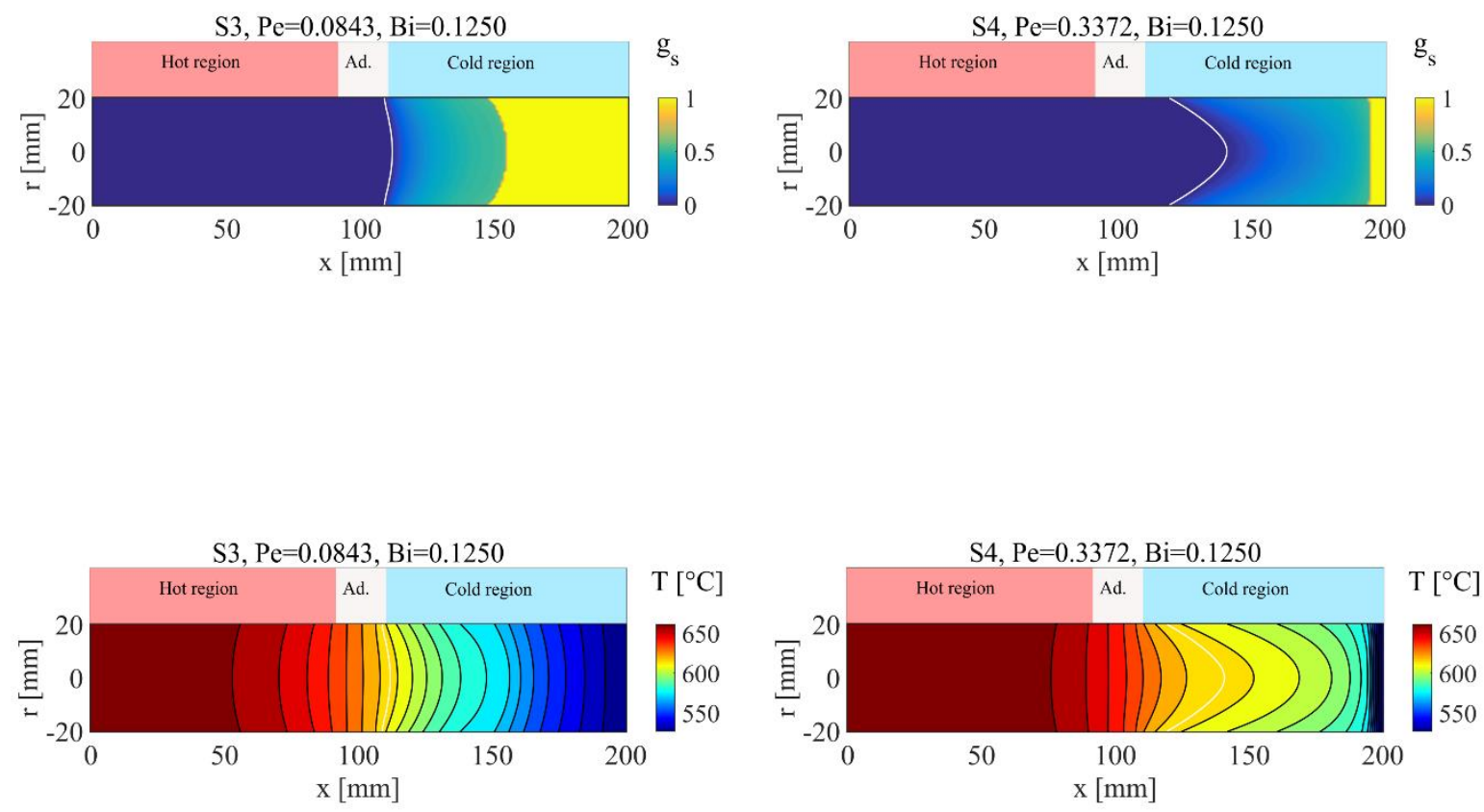

Figure 10: Simulations S3 (left) and S4 (right) showing the solid fraction (top) and temperature distribution (bottom) in an axial section of the samples during the pulling stage $(\mathrm{Pe}>0)$. 

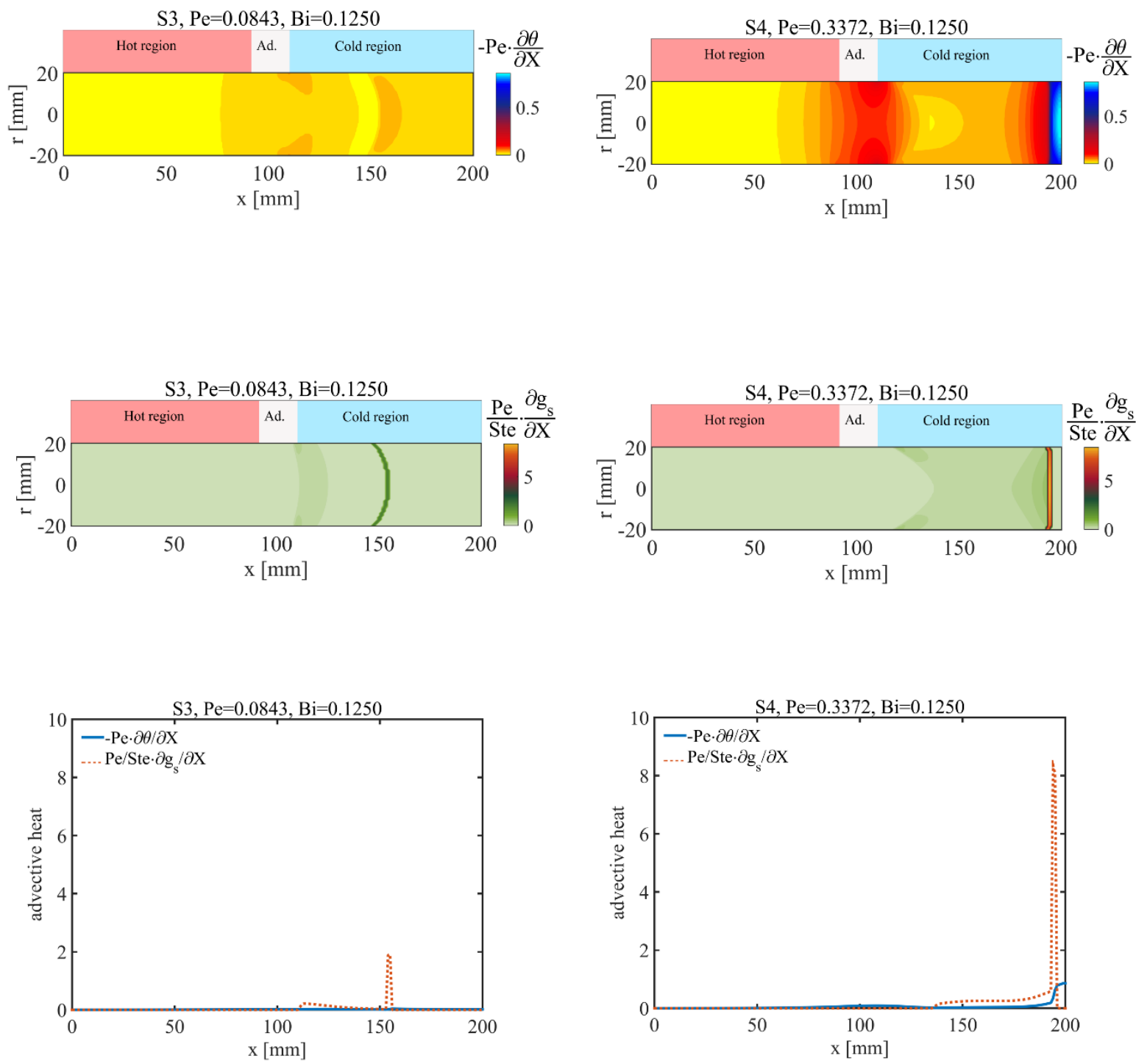

Figure 11: Simulations S3 (left) and S4 (right) showing the advective sensible heat term $-P e \frac{\partial \theta}{\partial X}$ (top), the advective latent heat term $\frac{P e}{\text { Ste }} \frac{\partial g_{s}}{\partial X}$ (middle), and the comparison of the two terms at $r=0$; note that these terms are dimensionless.

Figure 10 shows the steady state solution of solid fraction and temperature during the pulling stage for simulations S3 and S4, corresponding to $P e=0.0843(P e / S t e=0.4)$ and $P e=0.3372(P e / S t e=1.598)$ respectively. It is noticed from the temperature plots of Figure 10 as well as the liquidus isotherm profiles of Figure 8 that radial gradients are significantly higher for $\mathrm{S} 4$ even though the Biot number is the same for both cases, at $B i=0.125$. As implied considering $\mathrm{S} 2$ discussed above, the reason for this is that for certain cases advective thermal transport within the material can be significant and $B i$ does not account for this as it only scales the relative magnitude of conduction within the sample and convection at the boundaries. To highlight this, Figure 11 shows the distribution of the dimensionless rate of sensible heat flow by advection, $-P e \cdot \partial \theta / \partial X$ (top), and latent heat flow by advection, $P e / S t e \cdot \partial g_{s} / \partial X$ (middle). Since these terms are dimensionless, Figure 11 illustrates the relative magnitudes of the two advective thermal transport mechanisms in order to reveal which one is dominant and over what region within the domain. When the pulling velocity is lower, $P e$ is lower. Therefore, in simulation S3 the advective terms are weaker and the mushy zone is located partially within the adiabatic zone and the curvature of the liquidus isotherm is low (Figure 8), similar to the case S1 described earlier.

Correspondingly, the length of the mushy zone is small. On the contrary, in simulation S4 Pe is significantly higher and both sensible and latent heat transfer by advection are more important. Advection causes the mushy 
zone to shift towards the cold end of the domain and the shape of the liquidus isotherm becomes notably more convex (Figure 8) due to enhanced radial heat transfer. Considering the scales of to Figure 11, it is clear that only the sensible heat advection is present in the single phase liquid and solid regions, whereas the latent heat advection is dominant within the mushy zone. Thus, advection of heat, both sensible and latent, can be an important factor in determining the thermal profile within the sample, which of course will influence the resulting grain structure of the resulting solid.
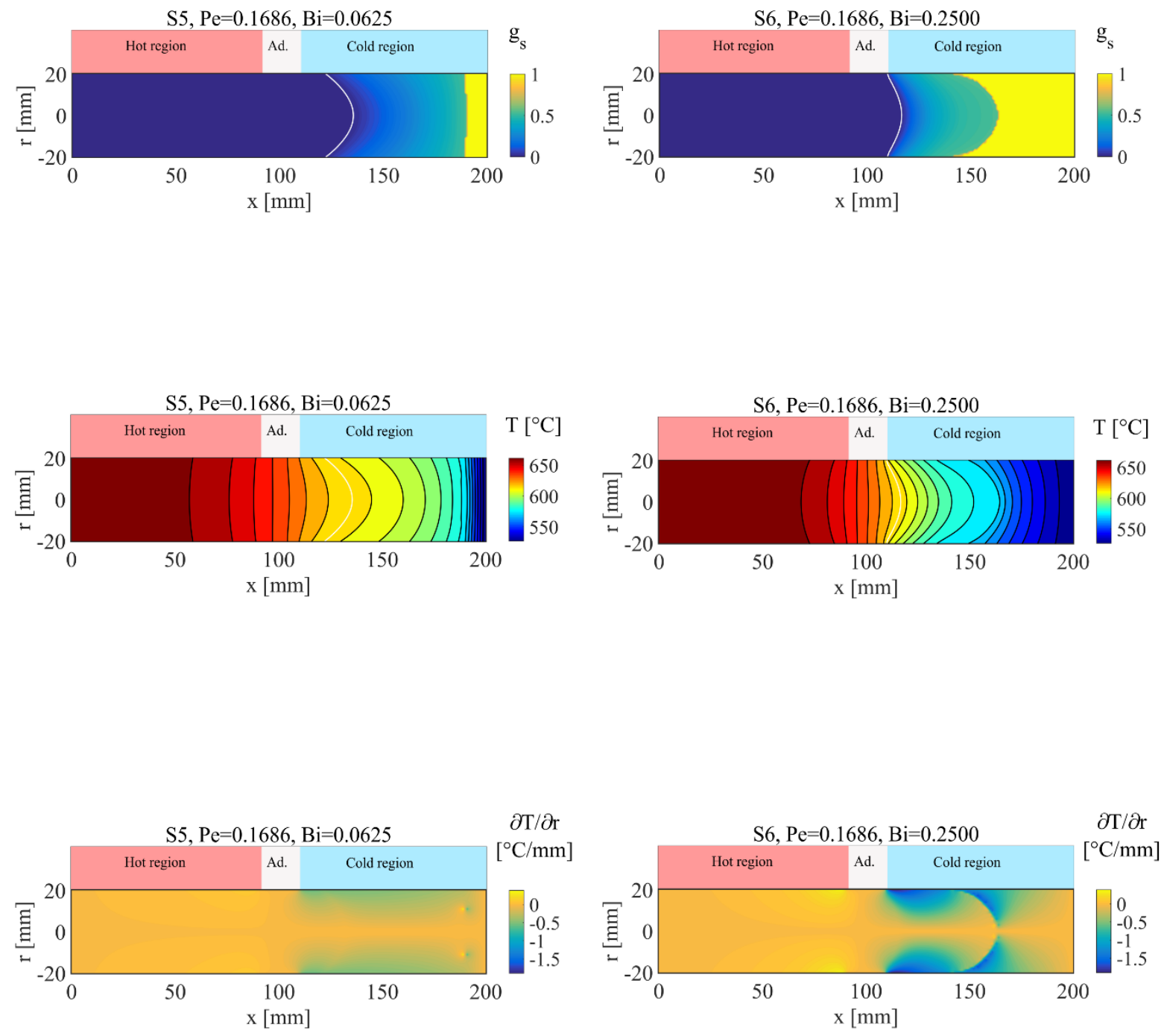

Figure 12: Simulations S5 (left) and S6 (right) showing the solid fraction, temperature distribution, and radial temperature gradient in an axial section of the samples during the pulling stage $(P e>0)$.

The above discussion indicates that $2 \mathrm{D}$ effects, here broadly considered by scrutinizing the shape of the liquidus isotherm, are strongly influenced by advective thermal transport. Above, the strength of this term was considered by increasing $P e$, by increasing the length and velocity scales separately. As it was shown, increasing $P e$ has the effect of increasing the curvature of the liquidus isotherm even for the case when $B i$ is identical. However, all of the above simulated cases have the same heat transfer coefficient, in the sense that $B i$ was altered by changing the radius of the sample. Figure 12, on the other hand, shows the radial temperature gradient distribution in the samples for simulations S5 and S6 correspond to $B i=0.0625$ and $B i=0.25$ respectively, where $B i$ is increased for S6 by increasing the heat transfer coefficient whilst keeping the dimensions the same as S5. 
For reference, the baseline S0 simulation corresponds to an intermediate case with $B i=0.125$ whilst having the same dimensions as S5 and S6. Each S0, S5 and S6 have the same $P e=0.1686$.

Simulation S5 has a lower Bi compared with the baseline S0 case. This would suggest that the radial thermal gradients in the sample would generally be weaker than S6 due to the lower relative thermal resistance of convective heat transport compared with that of radial conduction. In fact, the mean value of the radial temperature gradient in the cold heat sink region at the circumference is $\partial T / \partial r \approx-0.6^{\circ} \mathrm{C} / \mathrm{mm}$ in simulation $\mathrm{S} 0$ and $\partial T / \partial r \approx-0.4^{\circ} \mathrm{C} / \mathrm{mm}$ in simulation S5, showing the expected trend. Similarly, in simulation S6 Bi is larger than that of both the S0 and S5 cases and the magnitude of the radial heat flux increases as is clear in Figure 12. Here the mean value of the radial temperature gradient is $\partial T / \partial r \approx-0.8^{\circ} \mathrm{C} / \mathrm{mm}$. Thus, there is clear evidence that $B i$ in part determines the temperature distribution, including $2 \mathrm{D}$ radial effects, during Bridgman solidification of alloys due to the interplay of the conductive and convective thermal resistances. Interestingly however, Figure 8 shows that, compared with the baseline S0 case, the curvature of the liquidus isotherm increases in simulation S5 and decreases in simulation S6, which is opposite to what one would expect based purely on a Biot number scaling argument i.e. one that only includes convective and conductive thermal resistances to characterize 2D heat flow.

This behaviour can be understood by observing the position of the mushy zone in the sample. It is evident that in simulation S5 the liquidus isotherm is located much deeper in the heat sink region even though $P e$ is the same as in S6. As discussed earlier, the radial heat fluxes are generally higher due to the relative location of the mushy zone with respect to thermal communication with the cold heat sink walls, since the latent heat generated during the phase change induces higher temperature gradient between the sample and the cold boundary. On the contrary, in simulation S6 the liquidus is located at the border region between the adiabatic and heat sink zone where the isotherms are inherently flatter. Although the location of the mushy zone accounts for the enhanced (S5) or the reduced (S6) curvature of the liquidus isotherm, the reason for the different positions is not immediately clear since the magnitude of advection, as defined by the scale of $P e$, is the same in both simulations.

However, this could be understood by considering the meaning of the ratios $\mathrm{Bi} / \mathrm{Pe}$ and $\mathrm{Bi} /(\mathrm{Pe} / \mathrm{Ste}$.) In fact, these two terms could be regarded to as the ratios of the sensible and latent heat advective resistances inside the sample to the convective resistance at the boundary, respectively. Therefore, when $h$ is lower (S5), $B i / P e$ and $\mathrm{Bi} /(\mathrm{Pe} / \mathrm{Ste})$ diminish, which means that the sensible and latent heat advective resistances in the sample are relatively lower. As a consequence, the mushy zone moves deeper in the cold region due to the enhanced effect of advection. On the contrary, when the heat transfer coefficient is higher (S6), Bi/Pe and $\mathrm{Bi} /(\mathrm{Pe} / \mathrm{Ste})$ increase, hence the sensible and latent heat advective resistances in the sample are greater and the effect of advection is reduced. For the alloy under consideration in this work, this effect is dominated by the latter of the two, meaning that the advection of latent heat largely determines this effect, though it cannot be generally stated that this is true for all alloys and will be the focus of future study.

\section{Conclusions}

This investigation aimed to contribute to the understanding of Bridgman solidification. In particular, this work focussed on numerical simulations which included 2D effects and the interaction of advective thermal transport mechanisms. With reference to the stated objectives: the following steps were addressed:

1) A new $2 \mathrm{D}$ axisymmetric numerical model for Bridgman solidification of binary alloys was developed.

2) Key non-dimensional quantities that influence the evolution of temperature and solid fraction during solidification were identified as Stefan number, Péclet number, and Biot number.

3) The efficacy of the model was tested by simulating a suitable and relevant experimental test case [18].

4) A parametric analysis of the Bridgman solidification process was performed so as to contribute to the understanding of the influence of different parameters on temperature and solid fraction evolution.

The main conclusions from this study are as follows:

The Bridgman solidification process of binary alloy systems that exhibit a freezing range is characterized by several mechanisms of heat transfer. In particular, there is a strong interaction between the convective heat transfer at the boundaries, conduction and advection of sensible and latent heat in the sample. The parametric study showed that changing any of the process parameters, either in isolation or in combination, can induce significant and 
sometimes counter intuitive responses. This investigation suggest that, in order to anticipate the development of the mushy zone (position in the sample, shape of the mushy zone envelope), the single values of the dimensionless numbers $\mathrm{Bi}, \mathrm{Pe}$ and Ste might not be sufficient, and that considering the ratios $\mathrm{Pe} / \mathrm{Ste}, \mathrm{Bi} / \mathrm{Pe}$ and $\mathrm{Bi} /(\mathrm{Pe} / \mathrm{Ste})$ will give more relevant information on the process.

One advantage of the proposed model is the ability to reproduce both axial and radial thermal gradients. This is an important feature for investigating Bridgman solidification, since magnitude and direction of heat transfer at locations close to the liquidus isotherm could lead to the formation of different grain structures in front of the axial columnar grains, i.e. radial columnar or equiaxed grains [5]. In order to investigate the formation of different grain morphologies, plans for future work include the integration of a front tracking algorithm into the model. The front tracking method would facilitate the prediction of distinct regions in the mushy zone, namely columnar mush, equiaxed mush, or in the absence of equiaxed nucleation, constitutionally undercooled liquid regions.

\section{Acknowledgment}

This work was carried out as part of the GRADECET (Gravity Dependence of Columnar to Equiaxed Transition in Ti-Al alloys) research project, with the financial support of the European Space Agency PRODEX Programme (contract C4000110385) under the management of the Irish delegation to ESA within Enterprise Ireland. The authors would like to acknowledge Robin Patrick Mooney for providing technical discussion. Gratitude is also expressed to Gerhard Zimmermann and Laszlo Sturz for providing experimental data for comparisons.

\section{References}

[1] P.W. Bridgman, Certain Physical Properties of Single Crystals of Tungsten, Antimony, Bismuth, Tellurium, Cadmium, Zinc, and Tin, Proc. Am. Acad. Arts Sci. 60 (1925) 303.

[2] D.C. Stockbarger, The Production of Large Single Crystals of Lithium Fluoride, Rev. Sci. Instrum. 7 (1936) 133-136.

[3] D. Kang, J. Liu, C. Jiang, H. Xu, Control of solid-liquid interface morphology and radial composition distribution: TbDyFe single crystal growth, J. Alloys Compd. 621 (2015) 331-338. doi:10.1016/j.jallcom.2014.09.106.

[4] H. Jung, N. Mangelinck-Noël, H. Nguyen-Thi, B. Billia, G. Reinhart, A. Buffet, Directional solidification processing on CET in Al-based alloys, Met. Mater. Int. 15 (2009) 21-26. doi:10.1007/s12540-009-0021-z.

[5] R.P. Mooney, U. Hecht, Z. Gabalcová, J. Lapin, S. McFadden, Directional solidification of a TiAl alloy by combined Bridgman and power-down technique, Kov. Mater. - Met. Mater. 53 (2015).

[6] M. Gündüz, E. Çadırlı, Directional solidification of aluminium-copper alloys, Mater. Sci. Eng. A. 327 (2002) 167-185. doi:10.1016/S0921-5093(01)01649-5.

[7] D.R. Liu, N. Mangelinck-Noël, C. a. Gandin, G. Zimmermann, L. Sturz, H. Nguyen Thi, et al., Structures in directionally solidified Al-7 wt.\% Si alloys: Benchmark experiments under microgravity, Acta Mater. 64 (2014) 253-265. doi:10.1016/j.actamat.2013.10.038.

[8] W.U. Mirihanage, D.J. Browne, G. Zimmermann, L. Sturz, Simulation of international space station microgravity directional solidification experiments on columnar-to-equiaxed transition, Acta Mater. 60 (2012) 6362-6371. doi:10.1016/j.actamat.2012.08.015.

[9] E. Çadırlı, Effect of solidification parameters on mechanical properties of directionally solidified AlRich Al-Cu alloys, Met. Mater. Int. 19 (2013) 411-422. doi:10.1007/s12540-013-3006-X.

[10] J. Fan, J. Liu, S. Tian, S. Wu, S. Wang, H. Gao, et al., Effect of solidification parameters on microstructural characteristics and mechanical properties of directionally solidified binary TiAl alloy, J. Alloys Compd. 650 (2015) 8-14. doi:10.1016/j.jallcom.2015.05.160.

[11] J. Lapin, Z. Gabalcová, U. Hecht, R.P. Mooney, S. Mcfadden, Columnar to Equiaxed Transition in Peritectic TiAl Based Alloy Studied by a Power-Down Technique, Mater. Sci. Forum. 790-791 (2014) 193-198. doi:10.4028/www.scientific.net/MSF.790-791.193.

[12] R.H. Mathiesen, L. Arnberg, X-ray radiography observations of columnar dendritic growth and constitutional undercooling in an Al-30wt\%Cu alloy, Acta Mater. 53 (2005) 947-956. doi:10.1016/j.actamat.2004.10.050.

[13] S. McFadden, P.L. Schaffer, R.H. Mathiesen, D.J. Browne, Analysis of an Equiaxed Dendrite Growth Model with Comparisons to In-Situ Results of Equiaxed Dendritic Growth in an Al-Ge Alloy, Mater. Sci. Forum. 654-656 (2010) 1359-1362. doi:10.4028/www.scientific.net/MSF.654-656.1359. 
[14] H. Nguyen-Thi, G. Reinhart, G. Salloum Abou Jaoude, R.H. Mathiesen, G. Zimmermann, Y. Houltz, et al., XRMON-GF: A novel facility for solidification of metallic alloys with in situ and time-resolved Xray radiographic characterization in microgravity conditions, J. Cryst. Growth. 374 (2013) 23-30. doi:10.1016/j.jcrysgro.2013.03.032.

[15] G. Reinhart, H. Nguyen-Thi, N. Mangelinck-Noël, J. Baruchel, B. Billia, In Situ Investigation of Dendrite Deformation During Upward Solidification of Al-7wt.\%Si, Jom. 66 (2014). doi:10.1007/s11837-014-1030-z.

[16] G. Reinhart, N. Mangelinck-Noël, H. Nguyen-Thi, T. Schenk, J. Gastaldi, B. Billia, et al., Investigation of columnar-equiaxed transition and equiaxed growth of aluminium based alloys by X-ray radiography, Mater. Sci. Eng. A. 413-414 (2005) 384-388. doi:10.1016/j.msea.2005.08.197.

[17] A. Drevermann, L. Sturz, N. Warnken, G. Zimmermann, Investigation of the initial transient in directional solidification of binary AlCu alloys, Mater. Sci. Eng. A. 413-414 (2005) 259-262. doi:10.1016/j.msea.2005.08.164.

[18] G. Zimmermann, A. Drevermann, L. Sturz, N. Warnken, Time-dependent directional solidification of binary Al-Cu alloys in the initial transient, Int. J. Mater. Res. 98 (2007) 221-227. doi:10.3139/146.101454.

[19] D. Pelletier, P.J. Roache, Handbook of Numerical Heat Transfer, John Wiley \& Sons, Inc., Hoboken, NJ, USA, 2000. doi:10.1002/9780470172599.

[20] V. Timchenko, P.Y.P. Chen, E. Leonardi, G. De Vahl Davis, R. Abbaschian, A computational study of transient plane front solidification of alloys in a Bridgman apparatus under microgravity conditions, Int. J. Heat Mass Transf. 43 (2000) 963-980. doi:10.1016/S0017-9310(99)00176-3.

[21] V. Timchenko, P.Y.P. Chen, E. Leonardi, G. de Vahl Davis, R. Abbaschian, A computational study of binary alloy solidification in the MEPHISTO experiment, Int. J. Heat Fluid Flow. 23 (2002) 258-268. doi:10.1016/S0142-727X(02)00173-X.

[22] R.P. Mooney, S. McFadden, M. Rebow, D.J. Browne, A Front Tracking Model for Transient Solidification of Al-7wt\%Si in a Bridgman Furnace, Trans. Indian Inst. Met. 65 (2012) 527-530. doi:10.1007/s12666-012-0201-2.

[23] R.P. Mooney, S. McFadden, Order verification of a Bridgman furnace front tracking model in steady state, Simul. Model. Pract. Theory. 48 (2014) 24-34. doi:10.1016/j.simpat.2014.07.005.

[24] R.P. Mooney, S. McFadden, Z. Gabalcová, J. Lapin, An experimental-numerical method for estimating heat transfer in a Bridgman furnace, Appl. Therm. Eng. 67 (2014) 61-71. doi:10.1016/j.applthermaleng.2014.02.048.

[25] R. Mooney, S. Rex, L. Froyen, S. McFadden, O. Budenkova, D. Voss, et al., Review of the maxus 8 sounding rocket experiment to investigate solidification in a ti-al-nb alloy, (2011). doi:1609-042X.

[26] W.D. Bennon, F.P. Incropera, A continuum model for momentum, heat and species transport in binary solid-liquid phase change systems - I. Model formulation, Int. J. Heat Mass Transf. 30 (1987) 21612170. doi:10.1016/0017-9310(87)90094-9.

[27] J. Ni, F.P. Incropera, Extension of the continuum model for transport phenomena occurring during metal alloy solidification-I. The conservation equations, Int. J. Heat Mass Transf. 38 (1995) 1271-1284. doi:10.1016/0017-9310(94)00236-O.

[28] E. Scheil, Bemerkungen zur Schichtkristallbildung, Zeitschrift Für Met. 34 (1942) 70-72.

[29] S. McFadden, D.J. Browne, A front-tracking model to predict solidification macrostructures and columnar to equiaxed transitions in alloy castings, Appl. Math. Model. 33 (2009) 1397-1416. doi:10.1016/j.apm.2008.01.027.

[30] S. McFadden, D.J. Browne, C.A. Gandin, A Comparison of Columnar-to-Equiaxed Transition Prediction Methods Using Simulation of the Growing Columnar Front, Metall. Mater. Trans. A. 40 (2009) 662-672. doi:10.1007/s11661-008-9708-x.

[31] S. Patankar, Numerical heat transfer and fluid flow, Ser. Coputational Methods Mech. Therm. Sci. (1980) 1-197.

[32] W. Rosch, A. Fripp, W. Debnam, T.K. Pendergrass, Heat transfer measurements in the Bridgman configuration, J. Cryst. Growth. 137 (1994) 54-58. doi:10.1016/0022-0248(94)91246-7.

[33] W. Rosch, W. Jesser, W. Debnam, A. Fripp, G. Woodell, T.K. Pendergrass, A technique for measuring the heat transfer coefficient inside a Bridgman furnace, J. Cryst. Growth. 128 (1993) 1187-1192. doi:10.1016/S0022-0248(07)80121-7.

[34] M. Seredyński, S. Battaglioli, S. McFadden, A. Robinson, R.P. Mooney, Verification of a 2D Axisymmetric Model of the Bridgman Solidification Process for Metallic Alloys, in: Proc. Eurotherm Semin. 109 Numer. Heat Transf. 2015, Gliwice-Warsaw, 2015.

[35] W.L. Oberkampf, C.J. Roy, Verification and Validation in Scientific Computing, Cambridge University Press, 2010. 